PO050

\title{
WHITENESS FORMULA BASED ON CIECAM02 AND THEIR TEXTILE APPLICATION
}

\author{
Michal Vik et al.
}

DOI 10.25039/x46.2019.PO050

from

CIE x046:2019

Proceedings

of the

29th CIE SESSION

Washington D.C., USA, June 14 - 22, 2019

(DOI 10.25039/x46.2019)

The paper has been presented at the 29th CIE Session, Washington D.C., USA, June 14-22, 2019. It has not been peer-reviewed by CIE.

(C) CIE 2019

All rights reserved. Unless otherwise specified, no part of this publication may be reproduced or utilized in any form or by any means, electronic or mechanical, including photocopying and microfilm, without permission in writing from CIE Central Bureau at the address below. Any mention of organizations or products does not imply endorsement by the CIE.

This paper is made available open access for individual use. However, in all other cases all rights are reserved unless explicit permission is sought from and given by the CIE.

CIE Central Bureau

Babenbergerstrasse 9

A-1010 Vienna

Austria

Tel.: +4317143187

e-mail: ciecb@cie.co.at

www.cie.co.at 


\title{
WHITENESS FORMULA BASED ON CIECAM02 AND THEIR TEXTILE APPLICATION
}

\author{
Vik, M. ${ }^{1}$ and Viková, M. ${ }^{1}$ \\ ${ }^{1}$ Laboratory Color and Appearance Measurement, Technical University of Liberec, CZECH \\ REPUBLIC \\ michal.vik@tul.cz
}

DOI 10.25039/x46.2019.PO050

\begin{abstract}
Whiteness is an attribute of colors of high luminous reflectance and low purity situated in a relatively narrow region of the color space. The evaluation of whiteness of a product is dependent from the materials and the application it is used in. The most common acceptable formula for evaluation of white samples is the CIE whiteness index. The performance of the CIE whiteness formula is focused on D65 illuminant and narrow region of color space correlate not well under other conditions. Whiteness Vik-Vikova $W_{v v}$ whiteness formula was published on CIE Midterm meeting on Jeju Island, Korea 2017 is based on CIECAM02 color appearance model, respectively on its approximately uniform version called as CIECAM02UCS. A visual assessment study of the selected samples was carried out in order to relate the influence of the tint to perceive white. The results show that the new whiteness formula outperform other whiteness formulae in case of samples on the border of CIE Whiteness formula limits.
\end{abstract}

Keywords: e.g. Whiteness, CIE WI, fluorescent whitening agent, colorimetry, textiles

\section{Introduction}

Until now more than 100 whiteness indices had been developed (Choudhury 2014). Because appearance of whiteness is an important characteristic in many of industries due to consumer association a whiter appearance to better quality it is critical important to have whiteness index with highest possible correlation to human assessment. That means the issue is to develop formula that gives an appropriate weighting to the colorimetric parameters such as tristimulus values or reflectance.

Generally, are used three characteristics of near white materials, which are frequently misunderstood. First such term is Brightness, that measures the amount of reflectance of a specific wavelengths range of blue light. Basic scale is on interval of 0 to 100 , which mean the higher number is related to brighter appearance of near white material. Using the specific blue light to measure this reflectance, other mainly higher wavelengths as green and red are ignored. Due this limitation some type of near white materials with the same brightness can appear differently for observers. Other common term is therefore Whiteness, which is measure of light reflectance across all wavelengths of light comprising the full visible spectrum and it is obviously related to colorimetric parameters such as tristimulus values or chromaticity coordinates. Also, here higher value means higher perceived white of material. In case of presence FWA, the whiteness value reach frequently values above 100 , that means near white material appear as whiter than white. Last common term is Shade that is related to relatively weak color of near white materials. That means, shade represent subtle difference in color between near white materials. Shading allows increase of perceived white due to compensation of yellowish shade chemically bleached materials by the addition of blue colorants. This technique is also used in case of compensation of own color of FWA or in case of enhancement of perceived white under specific lighting condition when spectrum emitted by light source contains less amount of ultraviolet radiation. Some of white light sources are near to white light boundary, that means light itself is slightly colored. At these conditions is possible to improve perceived white of object by adding colorant that has complementary color to color of light source.

The most common acceptable formula for evaluation of white samples is the CIE whiteness index. Under D65 and CIE 1964 standard observer, the whiteness is given by: 


$$
W_{C I E}=Y+800\left(x_{0}-x\right)+1700\left(y_{0}-y\right),
$$

where $Y$ shows the brightness value and $x, y$ and $x_{n}, y_{n}$ are the chromaticity coordinates of the sample and the illuminant, respectively.

The CIE whiteness and tint equations were published in 1982, after more than 12 years of systematic study and consideration (Hirschler 2007). However, the application of the equations is restricted to samples that are called "white" commercially, that do not differ much in color and fluorescence, and that are measured on the same instrument at nearly the same time. These restrictions hinder the industrial application of these equations, and it would be important for the stakeholders to have the equations in such a way that their application conditions be less limiting. For example, in case of different light sources it is necessary to adapt parameters of CIE Whiteness formula. If are used tinted white samples frequently rating of whiteness made by observers is different in comparison to rating whiteness formula. In 2017 Vik and Viková published derivation of new whiteness formula based on linear formula following Ganz well known concept (Vik 2017).

$$
W_{V V}=0.84 \times J_{C A M 02}-7.59 \times b_{C C A M 02}+\left[-\frac{4}{9} \times\left(a_{c}\right)^{2}-\frac{4}{9} \times a_{c}+\frac{8}{9}\right]
$$

Magnitude, respectively measured quantities are with relation to CPWS and based on that formula gives values near to Ganz-Griesser linear whiteness formula. Main aim of this study is to test modification of Vik and Viková whiteness formula that gives values near to CIE whiteness equation.

\section{Materials and methods}

In the experiment was used set of selected 120 white textile samples. In order to prepare different white samples, the scoured and chemically bleached plain-woven cotton fabrics were treated with 4 different commercial FWAs, at 5 different concentrations and addition of 5 different concentration of 3 tinting dyes. CIE Whiteness of tested samples varies from 80 till 140 and tint values were in range of -5.5 to 6 units. Total radiance factor and computed luminescence factor of each sample was derived from CIBA Plastic White Scale, Avian white plastic set and LCAM Cotton White Scale s. 024/2017, which was used during calibration of Datacolor SF600+ spectrophotometer in de: $8^{\circ}$ mode. The measurement was carried out in the range 360 to $700 \mathrm{~nm}$ at $5 \mathrm{~nm}$ intervals. For comparison and correction was measured the same sample set by using bispectral method on Minolta Nisshimbo spectro-fluorimeter CM-3800d. Visual test were made in SPL III lighting cabinet with panel of 6 color normal observer.

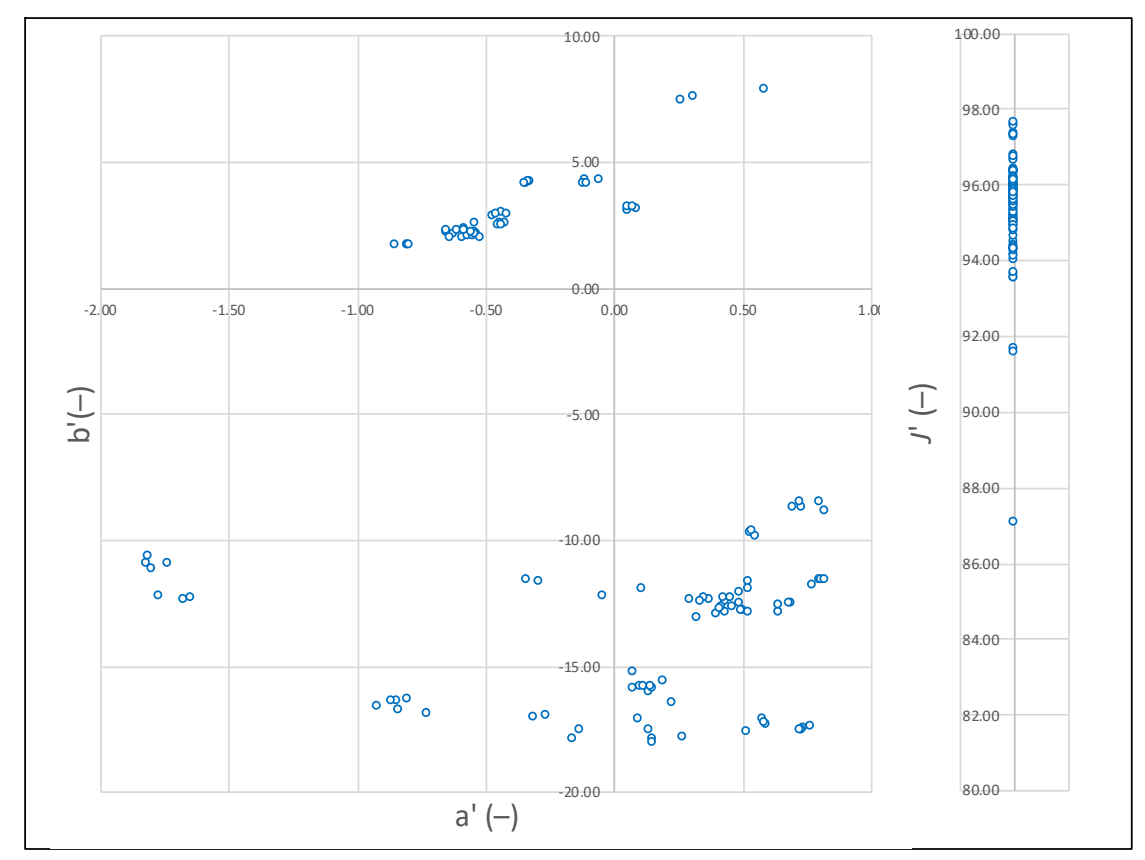

Figure 1 - Distribution of all produced cotton samples in CIECAM02UCS 
It is known that a white scale must consist of equal perceptual steps of white, i.e., the differences between the nominal whiteness values must match the visually perceived differences. It should represent a whiteness perceived as roughly neutral but with no implication of quality judgment. Also, its spectral properties should resemble as closely as possible those of the samples to be measured, because the sample illumination in measuring instruments differs to a greater or lesser extent from the standard illuminants used for the calculations. Also, it is known that it depends on a number of individual properties of the measuring instrument used. The entire geometry of the illuminating chamber - generally speaking a sphere is used for samples with a structured surface - is incorporated in the measuring results. The size of the aperture and the exclusion or inclusion of gloss also influence reflectance. High whiteness is obtainable only with the aid of fluorescent whitening agents (FWAs), and is hence a fluorescent color, which demands specific qualities of the illumination. The sample illumination must be identical with that for which the colorimetric values have been calculated. Nowadays, however, this is usually standard illuminant D65, which can be simulated only approximately in measuring instruments. In addition, all lamps used are subject to changes in spectral energy distribution. The problem is how to obtain constant, comparable results, namely whiteness, tint, and lightness for fluorescent materials using measuring instruments of different designs incorporating different means of simulating standard illuminant D65 or other D illuminants, allowing as high as possible color fidelity (Vik 2018).

Due to this reason we made two independent tests. First one was test of traceability of GanzGriesser calibration, which is based on UV/VIS ratio control by using of cut-off filter $400 \mathrm{~nm}$ (alternatively $395 \mathrm{~nm}$ ). In Laboratory Color and Appearance Measurement on Faculty of Textile Engineering of Technical University of Liberec (LCAM) were tested 6 spectrophotometers made by Datacolor International. Final results show acceptable traceability of all measurements, because resulting whiteness values were in expected interval of Ganz-Griesser calibration with use of Hohenstein White Scale (2.5 unit of Ganz-Griesser whiteness). Nevertheless, this test is insufficient because it is strongly dependent on only one scale, which is in point of view of traceability related to CIE illuminant D65. Correlation graphs are presented in Figure 2 together with results of linear regression in Table 1. It is visible strong correlation between both devices in point of view of CIE Whiteness. Correlation in CIE Tint value is probably affected by difference between theoretical spectral power distribution of illuminant CIE D65 used for calculation of total radiance factor in CM-3800d, filtered xenon flash in SF600Plus apparatus, and some differences in integrating sphere design.
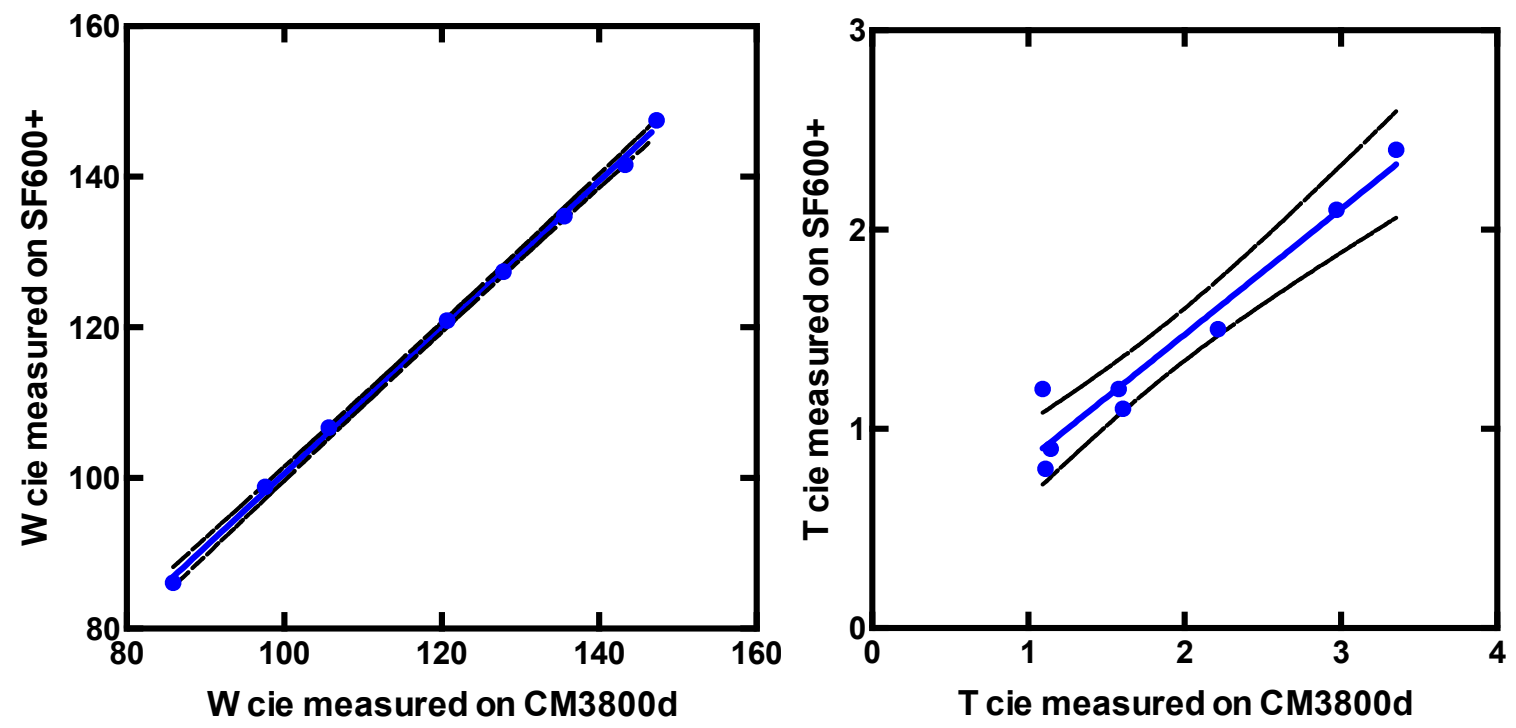

Figure 2 - Correlation between CM3800d and SF600Plus - CIE whiteness (left), CIE tint (right) 
Table 1 - Linear regression result for CM-3800d and SF600Plus with use of set AVIAN white plastic tiles

\begin{tabular}{|c|c|c|}
\hline Best-fit values & Whiteness CIE & Tint CIE \\
\hline Slope & $0.9712 \pm 0.01313$ & $0.6300 \pm 0.06467$ \\
\hline$Y$-intercept when $X=0.0$ & $3.458 \pm 1.606$ & $0.2130 \pm 0.1329$ \\
\hline$X$-intercept when $Y=0.0$ & -3.56 & -0.3382 \\
\hline 1/slope & 1.03 & 1.587 \\
\hline \multicolumn{3}{|l|}{ 95\% Confidence Intervals } \\
\hline Slope & 0.9391 to 1.003 & 0.4717 to 0.7882 \\
\hline$Y$-intercept when $X=0.0$ & -0.4717 to 7.387 & -0.1123 to 0.5383 \\
\hline$X$-intercept when $Y=0.0$ & -7.862 to 0.4703 & -1.121 to 0.1450 \\
\hline \multicolumn{3}{|l|}{ Goodness of Fit } \\
\hline R square & 0.9989 & 0.9405 \\
\hline Sy.x & 0.7729 & 0.1503 \\
\hline \multicolumn{3}{|l|}{$\begin{array}{l}\text { Is slope significantly non- } \\
\text { zero? }\end{array}$} \\
\hline $\mathrm{F}$ & 5469 & 94.89 \\
\hline DFn, DFd & $1.000,6.000$ & $1.000,6.000$ \\
\hline$P$ value & $<0.0001$ & $<0.0001$ \\
\hline Deviation from zero? & significant & significant \\
\hline $\begin{array}{l}\text { Data } \\
\text { Number of } X \text { values }\end{array}$ & 8 & 8 \\
\hline $\begin{array}{l}\text { Maximum number of } \mathrm{Y} \\
\text { replicates }\end{array}$ & 1 & 1 \\
\hline Total number of values & 8 & 8 \\
\hline Number of missing values & 0 & 0 \\
\hline Equation & $Y=0.9712^{*} X+3.458$ & $Y=0.6300 * X+0.2130$ \\
\hline
\end{tabular}

Visual assessment of whiteness and tint was made by look up method from two scales. As visual whiteness scale was used LCAM Cotton Whiteness Scale containing 9 samples with whiteness step around 9.5 unit starting at Wcie $=70$, till Wcie $=145$. LCAM CWS is almost neutral scale, with slight general CIE tint value -1.8. As tint scale was used grey scale for evaluation of staining following ISO 105-A03 standard. Orientation of tint difference was the same as in CIE Tint index, that means color shift to green direction was positive and to red direction as negative, with correction to neutral tint line of LCAM CWS itself. Each observer made 3 replications.

\section{Results and discussion}

The reflectance of the samples was measured to calculate the CIE colorimetric values. The CIE whiteness index, the tinting factor and other whiteness formulas of all fabrics were determined with use LCAM Colorimetry software made in MS Excel. Charts in Fig. 3 show that correlation between CIE Whiteness and visually assessed whiteness is relatively weak. Similar situation is visible in case of CIE tint index and visually assessed tint, where is correlation slightly better. 

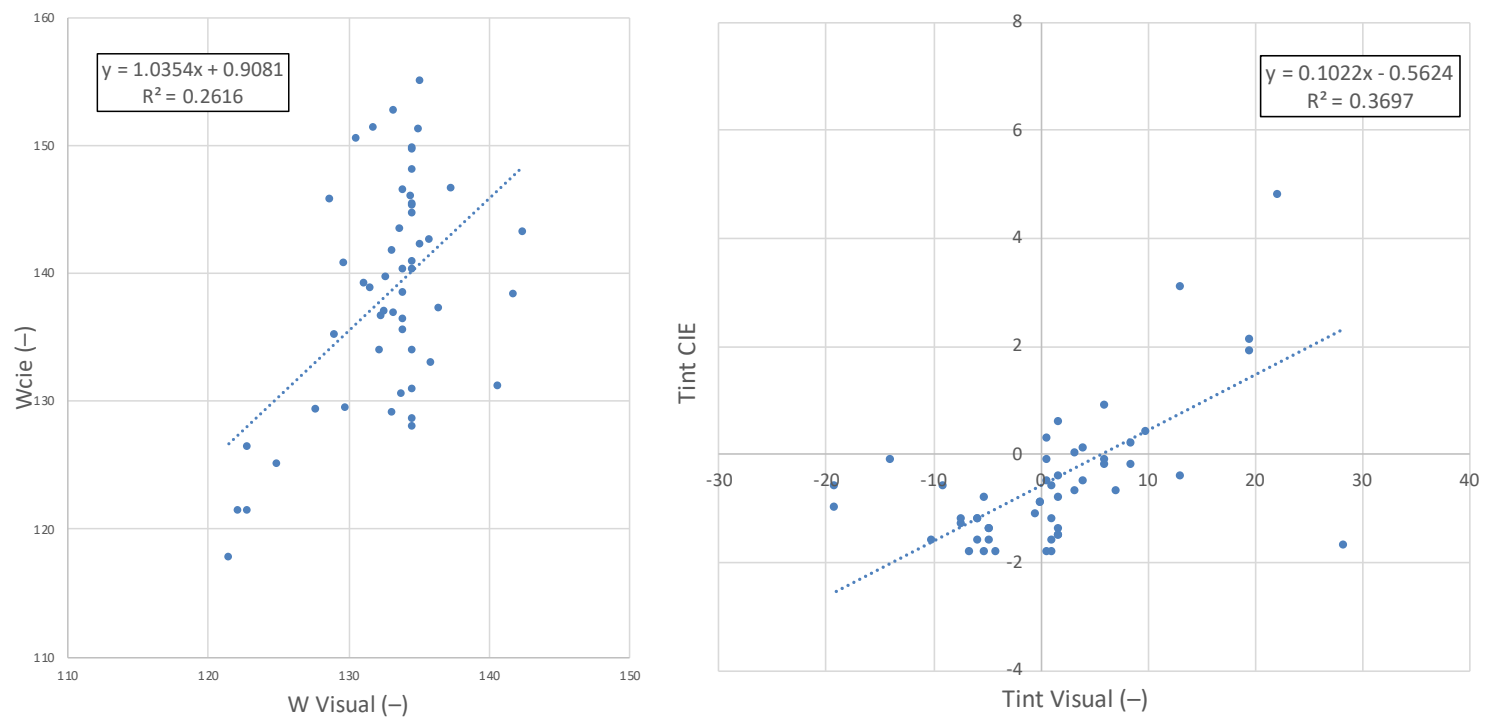

Figure 3 - Correlation between CIE Whiteness and Tint formula with visual assessment

When we analyzed subjective evaluation of data we found that evaluation of two observers was strongly scattered. Due to this result we reject these observers from evaluation and correlation of visual and instrumental whiteness was increased as it is shown on graph in Fig. 4.

It is visible that correlation of CIE whiteness formula gives almost identical results as its predecessor Ganz whiteness formula. Because range of tint of used samples was relatively narrow, correlation of Uchida whiteness formula is similar to. Worse correlation was found for Fleming-Aksoy whiteness formula probably due to relatively low brightness of some of tested samples. Slightly better result was obtained for old Berger whiteness formula, which was included in to test because in textile industry is still used. Best correlation was found for Vik Vikova whiteness formula probably due to correction of CIECAM02 on real luminance level in testing chamber, which was $306 \mathrm{~cd} . \mathrm{m}^{-2}$.

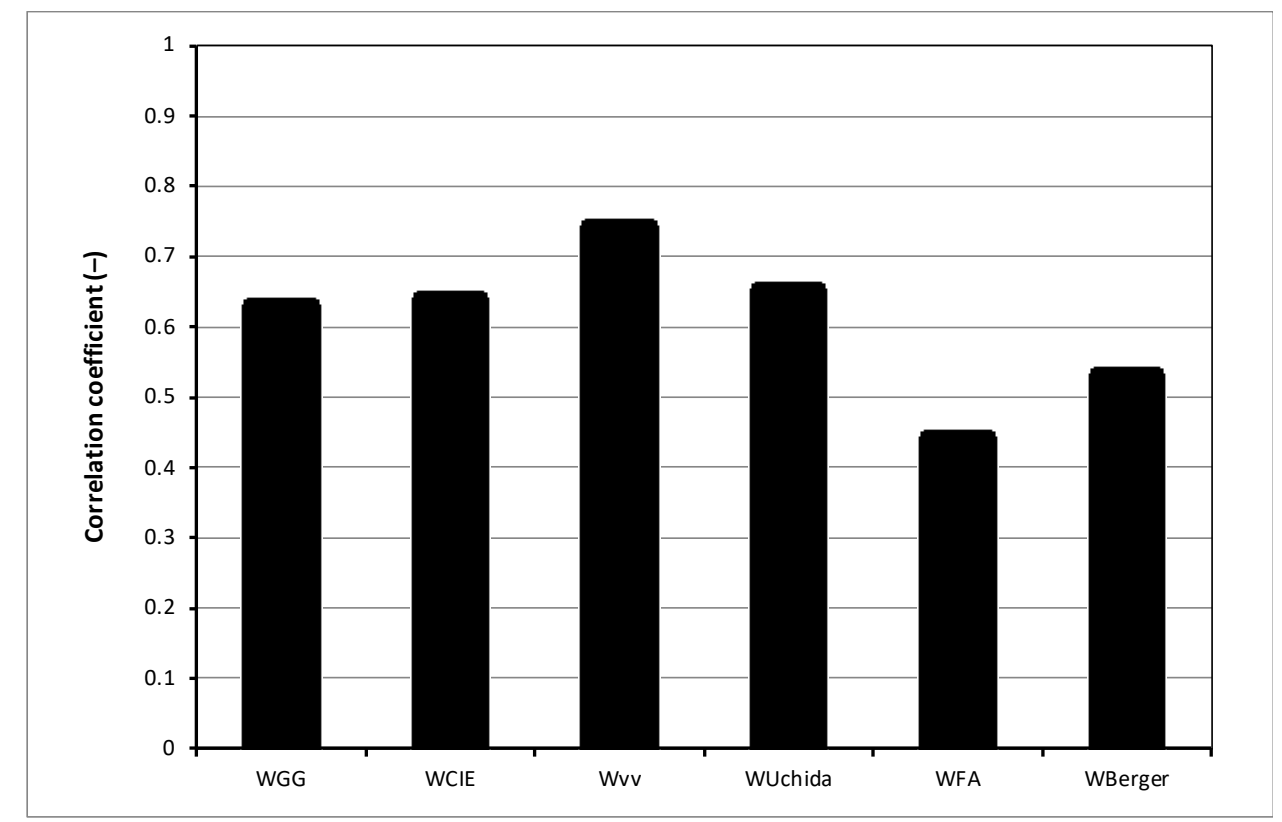

Figure 4 - Correlation coefficient of tested whiteness formulae

\section{Conclusion}

In practical terms, fluorescent whitening may reliably be predicted using tristimulus values measured by suitable calibrated spectrophotometer. In this paper, the performance of new 
whiteness formula and CIE whiteness formula was compared on set of white textile fabrics visually assessed under D65 simulator. From experimental study, it is revealed that new CIE CAM02 based whiteness index $W_{v v}$ is appropriate for the prediction of whiteness of tinted textile fabric in comparison to CIE whiteness formula.

\section{Acknowledgment}

This research was conducted at Technical University of Liberec and was funded by internal grant system. A very big thanks are given to Dr. Yuta Yamanoi from Konica-Minolta and Masayuki Osumi for their support.

\section{References}

[1] CHOUDHURY, A.K.R. 2014 Principles of colour appearance and measurement, Vol. 1, Cambridge: Woodhead Publishing.

[2] HIRSCHLER, R. \& ZWINKELS, J., 2007. Appendix 3: Use of CIE Colorimetry in the Pulp, Paper, and Textile Industries, Hoboken, NJ, USA: John Wiley \& Sons, Ltd.

[3] Vik, M., Viková, M. DEVELOPMENT OF WHITENESS FORMULA BASED ON CIECAM02, PROCEEDINGS of the Conference on "Smarter Lighting for Better Life" at the CIE Midterm Meeting 2017 October 23-25, 2017 Jeju, South Korea,

[4] VIK, M. \& VIKOVÁ, M., 2018. Color Rendition of Artificial Light Sources: Past and Future. In 7th Lighting Conference of the Visegrad Countries, LUMEN V4 2018 - Proceedings. IEEE, pp. 1-4. 